\title{
Assessment of Osteocalcin in Gingival Crevicular Fluid Around Bony Defect Treated with Platelet Rich Fibrin system
}

\begin{tabular}{l} 
Abeer M. Taiseer ${ }^{(\mathbf{1})}$, Hamdy A. \\
\hline \begin{tabular}{l} 
Codex : 61/1810 \\
azhardentj@azhar.edu.eg \\
http://adjg.journals.ekb.eg \\
\hline
\end{tabular}
\end{tabular}

\section{KEYWORDS}

Osteocalcin,

$G C F$,

ELISA,

PRF,

Bioactive glass and collagen membrane

\begin{abstract}
Purpose: to evaluate the effect of PRF system (PRF mixed with bone graft) in the regeneration of intra-bony defects by assessing osteocalcin in gingival Crevicular fluid. This study was accomplished on periodontal clinical and Radiographic evaluation. Subjects and Methods: A randomized double blind, split-mouth study was undergone on 12 patients with twenty four intrabony defects the selected defects were randomly divided into Group I (Test group): including eight defects that received PRF mixed with grafting material. Group II (Collagen group): including eight defects that received collagen membrane and PRF mixed with grafting material and Group III (Control group): including eight defects that received open flap debridement only. All subjects were put on a recall schedule where the clinical parameters (PI, GI, PD and CAL) and radiographic assessment(Alveolar bone height and bone density) were measured and recorded at base line and six months postoperatively. Results: Clinical outcomes in defects treated with collagen membrane and PRF mixed with grafting material (group II) showed more pocket reduction, greater gain in attachment level compared to other groups. However, better improvement in radiographic parameters was observed in defects treated with PRF mixed with grafting material (group I). Regarding mean osteocalcin concentration, defects treated with collagen membrane and PRF mixed with grafting material (group II) reported maximum reduction at the end of the study. Conclusions: The use of PRF as a regenerative material in managing periodontal intrabony defects resulted in pocket depth reduction, clinical attachment gain and defect fill with comparable results to bone graft and collagen membrane.
\end{abstract}

- A paper extracted from M.D. thesis entitled "Assessment of Osteocalcin in Gingival Crevicular fluid Around Bony Defects Treated with Platelet Rich Fibrin System"

1. Dentist in Ministry of Health

2. Professor of Oral Medicine, Periodontology, Diagnosis and Radiology. Faculty of Dental Medicine for Girls, Al- AzharUniversity.

3. Associate Professor of Oral Medicine, Periodontology, Diagnosis and Radiology, Faculty of Dental Medicine for Girls, Al- Azhar University.

4. Associate Professor of Oral Medicine, Periodontology, Diagnosis and Radiology, Faculty of Dental Medicine for Girls, Al- Azhar University. 


\section{INTRODUCTION}

Periodontal disease is one of the most common microbial infections. It is an inflammatory disease of bacterial origin that affects the tooth-supporting tissues, there are two major types of periodontal disease: gingivitis and periodontitis. Gingivitis involves a limited inflammation of the unattached gingiva, and is a relatively common and reversible condition. In contrast, periodontitis is characterized by general inflammation of the periodontal tissues ${ }^{(1)}$.The tissue destruction in periodontal disease appears as a result from the interplay between the pathogenic bacteria and the host's immune and inflammatory responses ${ }^{(2)}$.

Bone replacement grafts, such as autografts, allografts, xenografts, and alloplasts, remain among the most widely used therapeutic strategies for the correction of periodontal osseous defects ${ }^{(3)}$.

A barrier membrane is a device used in oral surgery and periodontal surgery to prevent epithelium, which regenerates relatively quickly, from growing into an area in which another, more slowly growing tissue type, such as bone, is desired. Such a method of preventing epithelial migration into a specific area is known as guided tissue regeneration $(\text { GTR })^{(4)}$.

Collagen membranes are of either type I or II collagen from cows or pigs. They are often crosslinked and take between four and forty weeks to resorb, depending on the type. Collagen absorbable barrier membranes do not require surgical removal, inhibit migration of epithelial cells, promote the attachment of new connective tissue, are not strongly antigenic and prevent blood loss by promoting platelet aggregation leading to early clot formation and wound stabilization ${ }^{(5)}$.

Evidence that the presence of growth factors and cytokines in platelets play key roles in inflammation and wound healing. Platelets also secrete fibrin, fibronectin, and vitronectin, which act as a matrix for the connective tissue and as adhesion molecules for more efficient cell migration ${ }^{(6)}$.
Platelet-rich fibrin (PRF) is a second generation platelet concentrate, which contains platelets and growth factors in the form of fibrin membranes prepared from the patient's own blood ${ }^{(7)}$. Moreover, The PRF clot forms a strong natural fibrin matrix, which concentrates almost all the platelets and growth factors of the blood harvest ${ }^{(8)}$.

Osteocalcin (OC.) is a non-collagenous matrix protein of calcifying and calcified tissue. It is produced by osteoblasts and has been described as the most specific marker of osteoblast function ${ }^{(9)}$. Osteocalcin has been found in GCF from patients with periodontal disease, and increases in Gingival Crevicular Fluid of OC concentration were associated with high rates of bone turnover, Raised levels of OC in GCF are reported in adult periodontitis may be related to the severity of breakdown and/or repair of alveolar bone ${ }^{(10,11)}$.

Thus The aim of the present study was to evaluate the effect of PRF system (PRF mixed with bone graft) in the regeneration of intra-bony defects by assessing osteocalcin in gingival Crevicular fluid

\section{PATIENTS AND METHOD}

A randomized double blind, split-mouth study was undergone on 24 patients with intrabony defects, selected consecutively from those referred to the Department of Oral medicine, Periodontology, Diagnosis and Radiology, Faculty of Dental medicine for Girls, Al- Azhar University seeking for periodontal treatment.Written consent was obtained from each subject, after explaining the study as well as giving information about the treatment and follow up appointments needed. Research Ethical Committee approval was obtained.

Inclusion criteria were; all selected patients were free from systemic illness, evaluated according to dental modification of the Cornell medical index ${ }^{(12)}$, all patients were diagnosed as having chronic periodontitis, Bilateral and/ or multiple defect with probing pocket depth was measured as $\geq 5$ and clinical attachment level $(\mathrm{CAL}) \geq 3^{(13)}$. Patients 
selected had not received any type of periodontal treatment in the past 6 months prior to examination, Patients were cooperative, had not received antibiotics or anti-inflammatory therapy in the 6 months prior to examination. Whereas the exclusion criteria were: Patients unwilling to undergo minor surgical procedure, Patients with history of drug abuse or catabolic drugs, Patients with any systemic condition that might contraindicate surgical therapy, Patients that had any habits that might jeopardize the regeneration process such as heavy smoking and alcoholism, Pregnant or lactating females.

The study groups; 24 intrabony defects were randomly divided into:Group I (Test group) including eight intrabony defects that have received bioactive glass mixed with PRF, Group II (Collagen group) including eight intrabony defects that have received collagen membrane with bioactive glass mixed with PRF and Group III (Control group) including eight intrabony defects that have received open flap debridement only.

Phase I therapy:Each patient first received cause- related therapy consisting of scaling and root planning, motivation, and oral hygiene instructions. Four weeks after the completion of initial therapy, re-evaluation examination was performed. At the base line clinical parameters were immediately preoperatively obtained on the day of the surgery by one examiner who was blind to the type of treatment. Final parameters were taken 1, 3 and 6 months preoperatively by the same examiner.

Surgical phase: sulcular incision was applied on the buccal and lingual/ palatal aspects of the involved teeth in addition to one tooth mesial and distal to it. Full thickness mucoperioesteal flap was then elevated by blunt dissection using periosteal elevator. The granulation tissue was then removed and thoroughly debridement was carried out with curettes, to ensure a clean site for incorporation of the graft material and membrane.

Protocol for PRF preparation: A sample of blood was collected from patient without anticoagulant in $10 \mathrm{ml}$ tubes which are immediately centrifuged at a rate of $3000 \mathrm{rpm}$ for $10 \mathrm{~min}$. after centrifugation; the resultant product consists of three layers. The top most layer consisting of cellular PPP (Platelet poor plasma), PRF clot in the middle and RBCs at the bottom of the test tube. The fibrin clot obtained after centrifugation is removed from the tube and the attached red blood cells were scraped off from it and discarded. Under aseptic condition, a fibrin clot formed in the middle part of the tube was obtained.

In group I, squeezed PRF mixed with bioactive bone graft settled within a sterile amalgam capsule that was inserted in amalgamator for 10 seconds. The final composite was inserted in the defect, the flap was adapted using vicryl suture. In group II, a surgical template was applied and trimmed, collagen membrane was cut according to formed template. After filling the defect with the grafting material, the membrane was adapted over the defect extending 2-3 $\mathrm{mm}$ apical to the crest of existing bone, and thenwas secured to the CEJ of the tooth with vicryl 4/0 suture. After finishing, the flap was secured with interrupted black silk 4/0 suture to obtain primary closure.

Regarding group III, open flap debridement was carried out. Thoroughly debridement of any defect had been performed without replacement of any graft material.

Post-operative instructions and medication: $\mathrm{Pa}$ tients were instructed to follow proper Oral hygiene measures including the use of soft brush regularly post-surgery, the use of $0.12 \%$ ChlorhexidineGluconate (2 times/day)(kahira Pharma \& Chemical Industries) for six weeks for assistance in plaque control. Antibiotic was prescribed as Augmentin $1 \mathrm{~g}$ tablet twice daily for five days to avoid possibility of infection. Also Brufen (400 mg tablets)was prescribed twice daily for 5 days to reduce inflammation, edema and pain.

Clinical Assessment: Clinical parameters were recorded at base line, one, three and six months;Pocket depth (PD), Clinical attachment level(CAL), Plaque index (PI), Gingival index(GI). 
Radiographic assessment: To standardize the measurements of Alveolar bone height preoperatively and postoperatively a line was drawn through the CEJ, another line was drawn perpendicular to the first line to the base of the pocket then the percentage of change in alveolar bone level (ABL \%) was calculated from the following equation ${ }^{(14)}$

$\mathrm{AB} L \%=\frac{\text { Distance from } C E J \text { to the base of osseous defect }}{\text { Root Length }} \times 100$

To measure bone density, we plot successive parallel lines to cover the surface area of the defect and indicate the gray level of each point on the lines, and then the mean value was taken. This represents bone density on the defect site. The mean gray value in each region of interest was calculated (256 gray levels of colors resolution) by assigning the gray value (0) to black, and the gray value (256) to white. Areas of bone loss represented as (dark areas), while areas of bone gain are (light areas). ${ }^{(15)}$

Biochemical assessment: The GCF osteocalcin analyzed by enzyme-linked immunosorbent assay (ELISA) for quantification of this protein in the GCF samples. All ELISA calibrations were performed in duplicate, Evaluation of periodontal disease progression was evaluated by taking GCF samples at base line, one month and three months postoperative.

\section{RESULTS}

The periodontal health status of all patients included in this study was assessed with criteria of Plaque Index (PI), Gingival Index (GI), Probing Pocket Depth (PD), as well as Clinical Attachment Level (CAL) at baseline, three and six months respectively. The data of all examined subjects included in the present study were recorded, tabulated, subjected to stastical analysiswherevalues were presented as mean and standard deviation (SD) values. Data were explored for normality using Kolmogorov-Smirnov test of normality. The results of Kolmogorov-Smirnov test indicated that most of data were normally distributed (parametric data), so one way analysis of variance ANOVA test was used to compare between groups and different intervals within the same group, followed by Tukey's post hoc test when the difference was found to be significant.

In all groups, plaque index decreased by time, to reach the least mean value after 6 months. One way analysis of variance revealed that there is a statistically significant decrease by time in group II $(\mathrm{P}<0.0001)$ and group III $(\mathrm{p}=0.031)($ table 1$)$.

Table (1): Plaque index in all groups and significance of the difference within the same group using ANOVA test

\begin{tabular}{|c|c|c|c|c|c|c|c|c|c|c|c|c|}
\hline & \multicolumn{4}{|c|}{ Group I } & \multicolumn{4}{|c|}{ Group II } & \multicolumn{4}{|c|}{ Group III } \\
\hline & BL & $1 \mathrm{M}$ & $3 \mathrm{M}$ & $6 \mathrm{M}$ & $\mathrm{BL}$ & M & $3 \mathrm{M}$ & $6 \mathrm{M}$ & $\mathrm{BL}$ & $1 \mathrm{M}$ & $3 \mathrm{M}$ & $6 \mathrm{M}$ \\
\hline Mean & 2.00 & 1.63 & 1.38 & 1.38 & $2.5^{\mathrm{a}}$ & $2.0^{\mathrm{a}}$ & $1.3^{\mathrm{b}}$ & $1.1^{\mathrm{b}}$ & $2.5^{\mathrm{a}}$ & $2.1^{\mathrm{a}}$ & $1.8^{\mathrm{a}, \mathrm{b}}$ & $1.6^{\mathrm{b}}$ \\
\hline SD & 0.76 & 0.74 & 0.52 & 0.52 & 0.5 & 0.5 & 0.5 & 0.4 & 0.5 & 0.8 & 0.5 & 0.5 \\
\hline Min & 1.00 & 1.00 & 1.00 & 1.00 & 2 & 1 & 1 & 1 & 2.00 & 1.00 & 1.00 & 1.00 \\
\hline Max & 3.00 & 3.00 & 2.00 & 2.00 & 3 & 3 & 2 & 2 & 3.00 & 3.00 & 2.00 & 2.00 \\
\hline F value & \multicolumn{4}{|c|}{1.68} & \multicolumn{4}{|c|}{14.78} & \multicolumn{4}{|c|}{3.14} \\
\hline P value & \multicolumn{4}{|c|}{$0.1939^{\text {ns }}$} & \multicolumn{4}{|c|}{$<0.0001^{*}$} & \multicolumn{4}{|c|}{$0.031 *$} \\
\hline
\end{tabular}

$B L=$ baseline, $M=$ month,$*$ Significant at $P<0.05$

Tukey's post hoc test: means sharing the same superscript letter (within the same group) are not significantly different. 
In all groups, gingival index decreased by time, to reach the least mean value after 6 months. One way analysis of variance revealed that there is a statistically significant decrease by time $(\mathrm{P}<0.0001$ in group I, II and $\mathrm{P}=0.032$ in group III) (table 2).

In all groups, probing depth decreased by time, to reach the least mean value after 6 months. One way analysis of variance revealed that there is a sta- tistically significant decrease by time in all groups $(\mathrm{P}<0.0001)$ (table 3).

In all groups, clinical attachment level decreased by the end of the study, to reach the least mean value after 6 months. One way analysis of variance revealed that there is a statistically significant decrease by time in all groups $(\mathrm{P}<0.0001)($ table 4$)$.

Table (2): Gingival index in all groups and significance of the difference between groups using ANOVA test

\begin{tabular}{|c|c|c|c|c|c|c|c|c|c|c|c|c|}
\hline & \multicolumn{3}{|c|}{ Baseline } & \multicolumn{3}{|c|}{1 month } & \multicolumn{3}{|c|}{ 3months } & \multicolumn{3}{|c|}{6 months } \\
\hline & GI & G II & GIII & GI & G II & GIII & GI & G II & GIII & GI & G II & GIII \\
\hline Mean & 2.63 & 2.5 & 2.4 & $2.38^{\mathrm{a}}$ & $1.6^{\mathrm{b}}$ & $2.1^{\mathrm{a}}$ & 1.63 & 1.4 & 1.9 & $1.38^{\mathrm{a}}$ & $1.1^{\mathrm{b}}$ & $1.8^{\mathrm{a}}$ \\
\hline SD & 0.52 & 0.5 & 0.5 & 0.52 & 0.5 & 0.4 & 0.52 & 0.5 & 0.4 & 0.52 & 0.4 & 0.5 \\
\hline $\mathrm{F}$ value & \multicolumn{3}{|c|}{0.46} & \multicolumn{3}{|c|}{5.3} & \multicolumn{3}{|c|}{2.27} & \multicolumn{3}{|c|}{3.39} \\
\hline$P$ value & \multicolumn{3}{|c|}{$0.637^{\mathrm{ns}}$} & \multicolumn{3}{|c|}{$0.0139 *$} & \multicolumn{3}{|c|}{$0.128^{\text {ns }}$} & \multicolumn{3}{|c|}{$0.036^{*}$} \\
\hline
\end{tabular}

Ns=non-significant,$*$ significant at $p<0.05$

Table (3): Probing depth ( $\mathrm{mm}$ ) in all groups and significance of the difference within the same group using ANOVA test

\begin{tabular}{|c|c|c|c|c|c|c|c|c|c|c|c|c|}
\hline & \multicolumn{4}{|c|}{ Group I } & \multicolumn{4}{|c|}{ Group II } & \multicolumn{4}{|c|}{ Group III } \\
\hline & BL & $1 \mathrm{M}$ & $3 \mathbf{M}$ & $6 \mathrm{M}$ & BL & $1 \mathrm{M}$ & $3 \mathbf{M}$ & $6 \mathrm{M}$ & BL & $1 \mathrm{M}$ & $3 \mathrm{M}$ & $6 \mathrm{M}$ \\
\hline Mean & $6.63^{\mathrm{a}}$ & $4.75^{b}$ & $3.88^{\mathrm{b}, \mathrm{c}}$ & $3.13^{\mathrm{c}}$ & $8.25^{\mathrm{a}}$ & $3.88^{b}$ & $3.13^{b}$ & $2.25^{\mathrm{b}}$ & $5.25^{\mathrm{a}}$ & $3.50^{\mathrm{b}}$ & $2.38^{\mathrm{b}, \mathrm{c}}$ & $2.38^{c}$ \\
\hline SD & 0.74 & 0.71 & 0.99 & 0.58 & 2.19 & 0.95 & 0.95 & 1.22 & 1.16 & 0.53 & 0.44 & 0.44 \\
\hline Min & 5 & 4 & 3 & 2 & 5 & 3 & 2 & 1 & 4 & 3 & 2 & 2 \\
\hline Max & 7 & 6 & 5 & 4 & 10 & 5 & 4.5 & 4 & 7 & 4 & 3 & 3 \\
\hline $\mathrm{F}$ value & \multicolumn{4}{|c|}{30.65} & \multicolumn{4}{|c|}{28.08} & \multicolumn{4}{|c|}{28.98} \\
\hline $\mathrm{P}$ value & \multicolumn{4}{|c|}{$<0.0001^{*}$} & \multicolumn{4}{|c|}{$<0.0001 *$} & \multicolumn{4}{|c|}{$<0.0001 *$} \\
\hline
\end{tabular}

Ns=non-significant,$*$ significant at $p<0.05$ 
Table (4): Clinical attachment level $(\mathrm{mm})$ in all groups and significance of the difference within the same group using ANOVA test.

\begin{tabular}{|c|c|c|c|c|c|c|c|c|c|c|c|c|}
\hline & \multicolumn{4}{|c|}{ Group I } & \multicolumn{4}{|c|}{ Group II } & \multicolumn{4}{|c|}{ Group III } \\
\hline & BL & $1 \mathrm{M}$ & $3 \mathbf{M}$ & $6 M$ & BL & $1 \mathrm{M}$ & $3 \mathbf{M}$ & $6 M$ & BL & $1 \mathrm{M}$ & $3 \mathrm{M}$ & $6 \mathrm{M}$ \\
\hline Mean & $4.00^{\mathrm{a}}$ & $2.00^{\mathrm{b}}$ & $1.50^{\mathrm{b}}$ & $0.38^{\mathrm{c}}$ & $4.50^{\mathrm{a}}$ & $1.75^{\mathrm{b}}$ & $1.63^{\mathrm{b}}$ & $0.63^{c}$ & $2.50^{\mathrm{a}}$ & $1.50^{\mathrm{b}}$ & $1.25^{\mathrm{b}}$ & $0.25^{\mathrm{c}}$ \\
\hline SD & 0.93 & 0.76 & 0.76 & 0.52 & 2.33 & 0.89 & 0.69 & 0.19 & 0.93 & 0.93 & 0.46 & 0.46 \\
\hline Min & 3.00 & 1.00 & 1.00 & 0.00 & 1.00 & 1.00 & 1.00 & 0.00 & 1.00 & 1.00 & 1.00 & 0.00 \\
\hline Max & 5.00 & 3.00 & 3.00 & 1.00 & 7.00 & 3.00 & 2.50 & 1.50 & 3.00 & 3.00 & 2.00 & 1.00 \\
\hline F value & \multicolumn{4}{|c|}{32.39} & \multicolumn{4}{|c|}{12.31} & \multicolumn{4}{|c|}{18.76} \\
\hline$P$ value & \multicolumn{4}{|c|}{$<0.0001^{*}$} & \multicolumn{4}{|c|}{$<0.0001^{*}$} & \multicolumn{4}{|c|}{$<0.0001 *$} \\
\hline
\end{tabular}

Ns=non-significant,$*$ significant at $p<0.05$

For each patient the radiographic assessments were interpreted to record bone fill and density for each intrabony defect before and after treatment. The mean of the readings at base line and six months was calculated, tabulated and subjected to statically analysis. In all groups, alveolar height decreased by time, to reach the least mean value after 6 months. Paired $\mathrm{t}$ test revealed that there is a statistically significant decrease by time in group I $(p=0.00012)$, group II and III $(\mathrm{P}<0.0001)$. At baseline, a greater mean alveolar height was recorded in groups I, II. At 6 months observation time, the greatest mean was recorded in group II, In all groups, alveolar density increased by time, to reach a higher value after 6 months. Paired $t$ test revealed that there is a statistically significant decrease by time in groups I \& II $(\mathrm{P}<0.0001)$, and group III $(\mathrm{p}=0.0003)$. At baseline and at 6 months after treatment, a greater mean alveolar density was recorded in group II. ANOVA test revealed that the difference between groups at baseline and 6 months was statistically significant ( $\mathrm{p}<0.0001$ and $\mathrm{p}=0.0006$ respectively) (table 5).

Table (5): Alveolar bone height and density in all groups and significance of the difference within the same group using paired t test

\begin{tabular}{|c|c|c|c|c|c|c|c|}
\hline \multirow{2}{*}{$\begin{array}{c}\text { Radiographic } \\
\text { parameter }\end{array}$} & & \multicolumn{2}{|c|}{ Group I } & \multicolumn{2}{|c|}{ Group II } & \multicolumn{2}{|c|}{ Group III } \\
\hline & & BL & $6 \mathrm{M}$ & BL & $6 \mathrm{M}$ & BL & $6 \mathrm{M}$ \\
\hline \multirow{6}{*}{ Alveolar bone height } & Mean & 38.5 & 19.5 & 38.25 & 21.5 & 29.25 & 20 \\
\hline & SD & 11.09 & 14.15 & 9.25 & 9.29 & 9.07 & 9.13 \\
\hline & Min & 28 & 7 & 28 & 10 & 20 & 10 \\
\hline & $\operatorname{Max}$ & 52 & 35 & 50 & 30 & 38 & 30 \\
\hline & $\mathrm{T}$ value & \multicolumn{2}{|c|}{7.665} & \multicolumn{2}{|c|}{10.251} & \multicolumn{2}{|c|}{18.839} \\
\hline & $\mathrm{P}$ value & \multicolumn{2}{|c|}{$0.00012^{*}$} & \multicolumn{2}{|c|}{$<0.0001 *$} & \multicolumn{2}{|c|}{$<0.0001 *$} \\
\hline \multirow{7}{*}{ Alveolar bone density } & & BL & $6 \mathrm{M}$ & BL & $6 \mathrm{M}$ & BL & $6 \mathrm{M}$ \\
\hline & Mean & 28.75 & 46.75 & 56.00 & 69.25 & 33.75 & 50.25 \\
\hline & SD & 7.46 & 13.30 & 2.71 & 3.30 & 17.11 & 13.94 \\
\hline & Min & 20.00 & 31.00 & 52.00 & 65.00 & 12.00 & 37.00 \\
\hline & Max & 38.00 & 62.00 & 58.00 & 73.00 & 51.00 & 69.00 \\
\hline & $\mathrm{T}$ value & \multicolumn{2}{|c|}{9.081} & \multicolumn{2}{|c|}{32.16} & \multicolumn{2}{|c|}{4.426} \\
\hline & $\mathrm{P}$ value & \multicolumn{2}{|c|}{$<0.0001 *$} & \multicolumn{2}{|c|}{$<0.0001 *$} & \multicolumn{2}{|c|}{$0.0003 *$} \\
\hline
\end{tabular}

Ns=non-significant,$*$ significant at $p<0.05$ 
ELISA analysis of the quantification of Osteocalcin before and after surgical periodontal therapy was performed for GCF samples collected from patients at baseline, one month and three months.

Table (6): Osteocalcin concentration ( $\mathrm{pg} / \mathrm{ml})$ in group I, II and III and significance of the difference by time within the same group using ANOVA test.

\begin{tabular}{|c|c|c|c|c|c|c|c|c|c|}
\hline & \multicolumn{3}{|c|}{ Group I } & \multicolumn{3}{|c|}{ Group II } & \multicolumn{3}{|c|}{ Group III } \\
\hline & BL & $1 \mathrm{M}$ & $3 \mathbf{M}$ & BL & $1 \mathrm{M}$ & $3 M$ & BL & $1 \mathrm{M}$ & $3 \mathbf{M}$ \\
\hline Mean & $0.262^{\mathrm{a}}$ & $0.037^{\mathrm{b}}$ & $0.039^{\mathrm{b}}$ & $0.033^{\mathrm{a}}$ & $0.032^{\mathrm{a}, \mathrm{b}}$ & $0.026^{\mathrm{b}}$ & $0.491^{\mathrm{a}}$ & $0.158^{\mathrm{b}}$ & $0.139^{\mathrm{b}}$ \\
\hline SD & 0.150 & 0.006 & 0.015 & 0.008 & 0.003 & 0.004 & 0.276 & 0.183 & 0.114 \\
\hline Min & 0.038 & 0.032 & 0.020 & 0.023 & 0.027 & 0.022 & 0.139 & 0.031 & 0.041 \\
\hline Max & 0.356 & 0.045 & 0.054 & 0.043 & 0.035 & 0.030 & 0.800 & 0.421 & 0.270 \\
\hline F value & \multicolumn{3}{|c|}{20.56} & \multicolumn{3}{|c|}{4.3} & \multicolumn{3}{|c|}{8.93} \\
\hline $\mathrm{P}$ value & \multicolumn{3}{|c|}{$<0.0001 *$} & \multicolumn{3}{|c|}{$0.027 *$} & \multicolumn{3}{|c|}{$0.0015^{*}$} \\
\hline
\end{tabular}

\section{DISCUSSION}

The hopeful goal of periodontal therapy is the regeneration of the lost part of the periodontium, i.e. the re-establishment of a normal periodontal apparatus (bone periodontal ligament and cementum) on a previously diseased root surface. The use of PRF is a recent and promising innovation in periodontal regenerative therapy. The positive impact of PRF on bone healing could be attributed to the angiogenic, proliferative and differentiating effects on osteoblasts of tissue growth factor $\beta$ and platelet derived growth factor (TGF- $\beta$ and PDGF) that are present in PRF in high concentrations ${ }^{(16)}$

GCF samples were collected by introducing filter papers in the crevice of the periodontal pocket until minimum resistance was felt and left for 30 seconds. This could provide a sample of sufficient size for analysis without changing the protein concentration of $\mathrm{GCF}^{(17)}$.

The collagen membrane was especially selected in this study in group II owing to its chemotactic nature to fibroblasts, it provides a scaffold for periodontal ligament cell migration, it is a weak immunogen and it can be easily manipulated and adapted $^{(18)}$.
Bioactive glass had been used as one of the bone graft substitutes, after implantation within the bony defect; surface reactions ensure deposition of a calcium phosphate layer when exposed to (body) fluid. Sodium, silica, calcium, and phosphate ions are released from the surface and increase the local $\mathrm{pH}$ and osmotic pressure ${ }^{(19)}$.

In the present study, there was a significant decrease in plaque index and gingival index in group I, II and group III at 3 and 6 months compared to the baseline. This could be attributed to the proper scaling and root planning, as well as the improvements in self-performed oral hygiene measures. The results of this study demonstrated a highly significant reduction in the probing depth at the end of the follow up period in the three studied group. Probing depth reduction may be attributed to attachment gain and tissue regeneration.

Moreover, this reduction may be due to the good adaptation of the flap following the surgery using the appropriate suturing technique. The mean reduction in probing depth in group I after 6 months was $3.13 \pm 0.58 \mathrm{~mm}$ which was in agreement with previous study ${ }^{(20)}$ reported $5.76 \pm 1.6 \mathrm{~mm}$ and $5.08 \mathrm{~mm}$ probing depth reduction respectively in 
treatment of intrabony defects. On the other hand, the mean probing depth reduction in group II was $2.25 \pm 1.22$ after 6 months. This was in accordance with studies carried by other study ${ }^{(21)}$ who found $3.3 \pm 6.5 \mathrm{~mm}$ mean probing depth reduction which was relatively comparable with the results of the present study. Whereas $2.38 \pm 0.44$ was the mean value of probing depth in group III.

There was a highly significant gain in the clinical attachment level in group I, II and III during the study period. The clinical attachment level gain was $3.62 \pm 0.41 \mathrm{~mm}$ in group I, $3.87 \pm 2.14 \mathrm{~mm}$ in group II and $2.25 \pm 0.47 \mathrm{~mm}$ in group III. These results were in agreement with other study ${ }^{(22)}$ who reported that the clinical and radiological effectiveness of autologous PRF in the treatment of intrabony defects of chronic periodontitis patients and reported a greater reduction in pocket depth, more gain in clinical attachment level and greater intrabony defect fill at sites treated with PRF than those treated with open flap debridement alone.

This study showed a significant bone fill in platelet rich fibrin treated group than in controls and a significant bone fill and gain in clinical attachment level in platelet rich fibrin combined with porous hydroxyapatite graft than in control group. Furthermore, the gain in clinical attachment level was $3.87 \pm 2.14$.

The amount of bone height gain was highly statistically significant increased at the end of the study period in group I, II and III. These results was analogous to those of previous studies ${ }^{(24,25)}$ in their case report assessed the clinical and radiographic changes in periodontal intrabony defects treated with PRF. They concluded PRF to be an effective treatment modality as the results showed that its application exhibited increased post-operative radiographic alveolar height in the treated defects.

Regarding bone density, there was a highly statistically significant increase in bone density in group I, II and III at 6 months. It was $17.7 \pm 5.84$ in group I, 13.25 \pm 0.59 in group II and $16.5 \pm 3.17$ in group III. It could be suggested that increased bone density in group I may be due to the combined competency of PRF as a cell proliferation, migration, and wound-healing agent together with its tissuespecific ability to promote osteoblast differentiation and new bone formation.

The current study demonstrated that by the end of the study there was a statistically significant reduction in the levels of the Osteocalcin in the three studied groups, whereas the mean values of $\mathrm{OC}$ at 3 months was $0.039 \pm 0.015,0.026 \pm 0.04$ and $0.139 \pm$ 0.114 in group I, II and III respectively compared to $0.262 \pm 0.150,0.033 \pm 0.008$ and $0.491 \pm 0.276$ mean values of OC at baseline in group I, II and III respectively. The high level of OC at baseline could be explained by the fact that Bone destruction is mediated by the host immune and inflammatory response to the microbial challenge. Our findings were in agreement with previous study ${ }^{(26)}$ whose study showed a significant reduction in GCF osteocalcin level in chronic periodontitis patients after SRP. A drop in the levels of GCF osteocalcin after periodontal therapy showed that osteocalcin increased with bone resorption and decreased with periodontal healing.

Results of this study revealed that there was statistically significant positive (direct) correlations between osteocalcin and different clinical parameters (PI, GI, PD and CAL). These data showed that OC levels are related to the progression of the disease. Its level was decreased when accurate treatment and maintenance of the patients occurred and vice versa.

Different regenerative modalities used in the present study resulted in favorable clinical, radiographic and biochemical changes. Clinical outcomes in defects treated with collagen membrane and combined bone graft and PRF (group II) showed more pocket reduction, greater gain in attachment level compared to other groups. However, better improvement in radiographic parameters were 
observed in defects treated with PRF mixed withgrafting material (group I). Regarding mean osteocalcin concentration, defects treated with collagen membrane and combined bone graft and PRF (group II) reported maximum reduction. This could be attributed to beneficial effects of PRF, collagen membrane and alloplast bone graft that facilitate the participation of progenitor cells in periodontal regeneration.

\section{REFERENCES}

1. Pejčić A, Peševska S, Grigorov I, et al. Periodontitis as a Risk Factor for General Disorders. ActaFacult Med Naiss 2006; 23:59-65.

2. Madianos PN, Bobetsis YA, Kinane DF. Generation of inflammatory stimuli: How bacteria set up inflammatory responses in the gingiva. J ClinPeriodontol 2005; 32:57-71

3. Reynolds MA, Aichelmann-Reidy ME, Branch-Mays GL, Gunsolley JC. The efficacy of bone replacement grafts in the treatment of periodontal osseous defects. A systematic review. Ann Periodontal 2003; 8:227-65

4. Carranza FA, McLain PK, Schallhorn RG: Regenerative Osseous Surgery. In Newman, Takei, Carranza, editors: Carranza's Clinical Periodontology, Philadelphia: W.B. Saunders Co. 2002; 9: 809.

5. Juodzbalys G, RaustiaAM, Kubilius. "A 5-year follow-up study on one-stage implants inserted concomitantly with localized alveolar ridge augmentation”. J Oral Rehabil. 2007; 34: 781-89.

6. Giannobile WV. Periodontal tissue engineering by growth factors. Bone 1996; 19:23S-37S.

7. Marx RE. Platelet-rich plasma: Evidence to support its use. J Oral MaxillofacSurg 2004; 62:489-496.

8. Choukroun J, Adda F, Schoeffer C, Vervelle A. PRF: an opportunity in perio-implantology. Implantodontie 2000; 42:55-62.

9. Toker H, Marakoglu I, Poyraz O. Effect of meloxicam on gingival crevicular fluid IL-1beta and IL1 receptor antagonist levels in subjects with chronic periodontitis, and its effects on clinical parameters. Clin Oral Investig 2006; 10:305-10.
10. Bullon P, Chandler L, Segura Egea JJ, Perez Cano R, Martinez Sahuquillo A. Osteocalcin in serum, saliva and gingival crevicularfluid:Their relation with periodontal treatment outcome in postmenopausal women. Med Oral Patol Oral Cir Bucal 2007; 12:193-97.

11. Griffiths. Formation, collection and significance of GCF. Periodontal 2003; 31, $32-42$.

12. Erdmann AJ, Brodman K, Lorge I, Wolff HG. Cornell Medical Index-Health Questionnaire. V. Outpatient admitting department of a general hospital. J Am Med Assoc. 1952; 149:550-51.

13. Loe H and Sillness J. periodontal disease in pregnancy. I. Prevalence and severity. ActaOdontol Scand. 1963; 21: 533-40.

14. Rosling B, Hollender L, Nyman S, Olsson G.Aradiographic method for assessing changes in alveolar bone height following periodontal therapy. J ClinPeriodontol. 1975; 2:211-17.

15. Berketa WJ, Hirsch SR, Higgins D, James H. Radiographic Recognition of Dental Implants as an Aid to Identifying the Deceased. J Forensic Sci. 2010; 55: 66-70.

16. Pradeep AR, Shetty SK, Garg G, Pai S. Clinical effectiveness of autologous platelet-rich plasma and Peptide-enhanced bone graft in the treatment of intrabony defects. $\mathrm{J}$ Periodontal. 2009; 80:62-71.

17. Lamster IB and Ahlo JK. Analysis of gingival crevicular fluid as applied to the diagnosis of oral and systemic diseases. Ann New York Acad science, 2007; 1098: 216-29

18. Mattson JS, Gallagher SJ, Jabro MH. The use of 2 bioabsorbable barrier membranes in the treatment of interproximal intrabony periodontal defects. J periodontal 1999; 70: 510-19.

19. Coraça-Huber DC, Fille M, Hausdorfer J, Putzer D, Nogler M. Efficacy of antibacterial bioactive glass S53P4 against $\mathrm{S}$. aureus biofilms grown on titanium discs in vitro, Journal of Orthopaedic Research, 2014; 32: 175-77.

20. Momose TM, Murata M, Saito Y, Suzuki H, Wolff LF, Yoshie HJ. Platelet-rich plasma contains high levels of platelet-derived growth factor and transforming growth factor-beta and modulates the proliferation of periodontally related cells in vitro.Okuda K, Kawase. 2003; 74:849-57. 
21. Vourous I, Aistodimou E, Konstantinidis A. guided tissue regeneration in intrabony periodontal defect following treatment with two bioabsorbable membranes in combination with bovine bone mineral graft. A clinical and radiographic study. J Clin periodontal 2004; 31: 908-11

22. Flip K, Tisun K, Stafen H, Hans-Jorg S, Peter R, Rolf H, Peter E. Radiographic defect depth and width for prognosis and description of periodontal healing of intrabony defects. J periodontal 2001; 72:1639-47.

23. Sharma A, Pradeep AR. Autologous platelet-rich fibrin in the treatment of mandibular degree II furcation defects: a randomized clinical trial. J Periodontol 2011; 82: 1396-403.
24. Trejo PM, Weltman R, Caffesse R. Treatment of intraosseous defects with bioabsorbable barriers alone or in combination with decalcified freeze-dried bone allograft: a randomized clinical trial. J Periodontol. 2005; 71:1852-56.

25. Schwartz Z, Goultschin J, Dean DD, Boyan BD. Mechanisms of alveolar bone destruction in periodontitis, Periodontology 2000; 14:158-72.

26. Assad AM, Una ME, Hesham A, Reham ME. Assessment of 25-Hydroxy Vitamin D3 and Osteocalcin in Chronic Periodontitis Patient (Clinical and Laboratory Study). Mansoura Journal of Dentistry 2014; 1: 34-41. 